\title{
Characterization of Membrane Homing Receptors in Two Cloned Murine Hemopoietic Progenitor Cell Lines
}

\author{
Takashi Matsuoka, Cheryl Hardy, and Mehdi Tavassoli \\ Veterans Administration Hospital and University of Mississippi School of Medicine, Jackson, Mississippi 39216
}

\section{Abstract}

To characterize homing receptors that are responsible for the recognition and specific binding of hemopoietic progenitor cells to the stroma, we synthesized and ${ }^{125}$ I-labeled a number of neoglycoproteins. We used these neoglycoproteins as ligand to detect receptors on the membrane of two cloned murine hemopoietic progenitor cell lines, B6SUT and FDCP-1. Both cell lines demonstrated membrane receptors with galactosyl and mannosyl, but not fucosyl, specificities. B6SUT galactosyl receptors showed a single receptor population with a $K_{d}$ of about $2.3 \times 10^{-7} \mathrm{M}$ and $10^{6}$ receptors per cell. Mannosyl receptors demonstrated two components with high and low affinities respectively with $K_{d}$ of about $2.5 \times 10^{-8} \mathrm{M}$ and $1.0 \times 10^{-7} \mathrm{M}$, and respectively about $7.4 \times 10^{5}$ and $3.7 \times 10^{5}$ receptors per cell. Comparable data were also obtained for FDCP-1. Displacement experiments indicated that radioactive ligands bound to receptors could be increasingly displaced by homologous cold ligand giving typical sigmoid-shaped curves. Cold mannosyl probe could also displace radioactive galactosyl probe in a similar manner, but cold galactosyl probe displaced radioactive mannosyl ligand with a curve demonstrating two phases, further suggesting two receptor components for the mannosyl ligand. Mature murine neutrophils and red cells as well as human neutrophils, monocytes, and red cells showed no receptors. The functional significance of these receptors in binding to stromal cells was demonstrated by quantitation of the binding of ${ }^{51} \mathrm{Cr}$-labeled progenitor cells to the cloned stromal cell line, D2X, before and after enzymatic removal of various carbohydrate residues of membrane glycoconjugates. Enzymatic removal of galactosyl and mannosyl, but not fucosyl, residues almost totally eliminated the binding. The findings strongly suggest that these homing receptors are present on the surface of early hemopoietic progenitor cells. With maturation the cells lose their receptors, so that mature cells can be released into the blood stream.

\section{Introduction}

Hemopoiesis is the result of interactions between hemopoietic stem cells (HSC) ${ }^{1}$ and their supporting stroma (1-3). The earli-

Address reprint requests to Dr. Tavassoli, Veterans Administration Medical Center (151), 1500 Woodrow Wilson Drive, Jackson, MS 39216.

Received for publication 13 June 1988 and in revised form 13 September 1988 .

1. Abbreviations used in this paper: ASF, asialofetuin; CFU-GM, granulocyte-macrophage progenitor; CFU-S, multipotential hemopoietic cell; D-PBS, Dulbecco's phosphate-buffered saline; GM-CSF, granulocyte-macrophage colony-stimulating factor; HSC, hemopoietic stem cell; M-CSF, macrophage-specific colony-stimulating factor.

The Journal of Clinical Investigation, Inc.

Volume 83, March 1989, 904-911 est event in this process involves specific recognition and binding (homing) of HSC to the stroma. This concept forms the frame of reference for bone marrow transplantation where a source of HSC is introduced into the general circulation in anticipation of their selective homing to the bone marrow (4, 5). This is in contrast to the transplantation of other organs which are placed orthotopically or heterotopically in the recipient's body and their vasculature are surgically connected.

Homing involves specific recognition of HSC and other marrow progenitor cells by stromal cells. There has been suggestive evidence that this recognition might be mediated by carbohydrate-protein interactions (6-8). To explore the nature of this recognition mechanism at a molecular level, we synthesized a number of probes by covalently binding $p$-aminophenyl derivatives of various sugars to bovine serum albumin (BSA) so that their pyranose form, necessary for lectin binding, would be preserved (9). These "neoglycoproteins" were utilized to inhibit homing of HSC and other progenitor cells, both in vivo and in vitro. We demonstrated that in both systems, the molecular basis of homing involves lectins with galactosyl and mannosyl specificities (10-12). Using agglutination techniques, we subsequently provided evidence (13) that these lectins (homing receptors) are located on the membrane of HSC and granulocytemacrophage precursor cells (CFU-GM).

In the present work, we have used these neoglycoproteins to characterize homing receptors on the membrane of two cloned murine cell lines, one with potential for differentiating into multiple hemopoietic lineages (B6SUT), and the other with restricted potential for differentiating into granulocytemacrophage lineage (FDCP-1). For control purposes, we have also demonstrated that these receptors are absent on the surface of mature, circulating neutrophils and erythrocytes. To demonstrate that these receptors are indeed involved in the binding of these progenitor cells to the stroma, we have quantified their binding to a cloned stromal cell line D2X with and without treatment with different enzymes to remove carbohydrate moieties that could be responsible for binding of progenitor cells. While treatment with sialidase (which exposes galactosyl residues) enhanced the binding, enzymatic removal of galactosyl and mannosyl residues almost totally eliminated the binding.

\section{Methods}

Cells. Two clones of progenitor cells were used. B6SUT is an interleukin 3 (IL-3)-dependent multipotential hemopoietic cell line, cloned from the nonadherent cell population of murine long term marrow cultures. It is capable of forming mixed colonies containing erythroid cells, neutrophilic granulocytes or basophil/mast cells in semisolid medium containing erythropoietin or conditioned medium from pokeweed mitogen-stimulated spleen cells (14-16). When infused intravenously into lethally irradiated mice, it homes to hemopoietic tissues where it proliferates and forms colonies (17). FDCP-1 is another cell line, similarly cloned from nonadherent cells of murine long-term bone marrow cultures. Its growth is dependent on the presence of IL-3 or granulocyte-macrophage colony-stimulating factor (GM-CSF), but not macrophage-specific colony-stimulating factor (M-CSF). This cell 
line can form granulocyte/macrophage colonies in semisolid medium under appropriate conditions $(18,19)$. None of these cell lines appears to contain viruses or viral genomic products.

B6SUT cells were grown in Kincade's medium supplemented with $10 \%$ five-times-concentrated WEHI-3B-conditioned medium as a source of IL-3. They were maintained at $31^{\circ} \mathrm{C}$ under $7 \% \mathrm{CO}_{2}$. They were fed twice weekly and maintained at a density of $\sim 10^{6}$ cells $/ \mathrm{ml}$. FDCP-1 cells were grown in RPMI 1640 medium supplemented with $10 \%$ five-times-concentrated WEHI-3B-conditioned medium, $10 \%$ fetal calf serum (Hyclone Laboratories, Sterile Systems, Inc., Logan, UT), $1 \%$ glutamine and $1 \%$ penicillin-streptomycin. They were maintained at $37^{\circ} \mathrm{C}$ under $5 \% \mathrm{CO}_{2}$. They were passed twice weekly at $\sim 10^{4}$ cells $/ \mathrm{ml}$. The potential of both cell lines for in vitro differentiation was confirmed independently in our laboratory.

For stromal cells, the cloned adherent stromal cell line D2X was used. This cell line has been cloned from long-term marrow cultures that were established from $\mathrm{C} 3 \mathrm{H} / \mathrm{HeJ}$ mice and is capable of binding marrow cells including the two progenitor cell lines mentioned above. This cell line was maintained in RPMI 1640 (Gibco, Grand Island, NY), supplemented with $10 \%$ FCS, $1 \%$ glutamine, and $1 \%$ penicillinstreptomycin (16). The cells were maintained at $33^{\circ} \mathrm{C}$ under $7 \% \mathrm{CO}_{2}$ and were passaged once a week following brief exposure to $0.25 \%$ trypsin. All three cell lines were provided through the courtesy of Dr. Joel Greenberger (Worcester, MA).

As negative controls, mature murine neutrophils and red blood cells were used. To obtain mature neutrophils, the marrow content of femurs and tibias from adult $\mathrm{C} 57 \mathrm{Bl} / 6$ mice, was flushed into a tube containing phosphate-buffered saline (PBS, pH 7.4) to which 100 $\mathrm{U} / \mathrm{ml}$ of heparin was added. The cells were washed twice in the same buffer by centrifugation and were subjected to gradient centrifugation on ficoll-hypaque (specific gravity 1.077). Mature neutrophils and red cells were recovered from the bottom of the tube and red cells were subsequently removed by hypotonic shock. Smears of cells were prepared and showed $>95 \%$ neutrophils. To prepare red cells, blood was obtained by cardiac puncture into heparinized syringes. Red cells were then agglutinated in 3\% dextran (clinical grade) to separate them from leukocytes. Red cells were then washed thrice in PBS (pH 7.4) by centrifugation at $200 \mathrm{~g}$ and resuspended in the buffer. In addition circulating red cells, neutrophils and monocytes from circulating blood of human volunteers were obtained (with informed consent) and separated by similar methods. The method for preparation of purified blood monocytes has been previously described $(20,21)$.

Neoglycoproteins and labeling. The method for the synthesis of neoglycoprotein probes has been established in our laboratory and described elsewhere in detail (9). Briefly, $p$-aminophenyl derivatives of $\beta$-D-galactose, $\alpha$-D-mannose, $\alpha$-L-fucose (all in pyranose form) were activated by thiophosgene and covalently bound to the amino groups of BSA. The ratio of sugar to protein was calculated to be about 25 .

Final preparation of neoglycoproteins was made in Dulbecco's phosphate-buffered saline (D-PBS). Concentration, (measured by the method of Lowry et al. [22]) was $3.4 \mathrm{mg} / \mathrm{ml}(0.05 \mathrm{mM}), 3.2 \mathrm{mg} / \mathrm{ml}$ $(0.047 \mathrm{mM})$, and $3.2 \mathrm{mg} / \mathrm{ml}(0.047 \mathrm{mM})$, respectively, for galactosyl (Gal-BSA), mannosyl (Man-BSA), and fucosyl (Fuc-BSA) neoglycoproteins. Carbohydrate concentration (measured by the orcinol sulfate method [23]), was $0.34 \mathrm{mg} / \mathrm{ml}(1.25 \mathrm{mM}), 0.52 \mathrm{mg} / \mathrm{ml}(1.92 \mathrm{mM})$, and $0.26 \mathrm{mg} / \mathrm{ml}(1.02 \mathrm{mM})$ respectively for the three preparations.

The method fulfills several theoretical requirements. (a) Binding of sugars to a larger protein molecule prevents diffusion of small sugar molecules into the cells. $(b)$ The protein itself does not have specific membrane receptors, but it permits labeling with ${ }^{125}$ I for binding studies. $(c)$ The sugar remains in pyranose form, necessary for binding to lectin or lectinlike substances. $(d)$ The sugar/protein ratio is high enough to permit the use of these neoglycoproteins as probes. $(e)$ The probes have been shown to be totally nontoxic (10). In addition, they have no hemopoietic stimulatory or inhibitory activity (10).

Neoglycoproteins were labeled with ${ }^{125}$ I by lactoperoxidase method (24). Briefly, $500 \mu \mathrm{l}$ of immobilized lactoperoxidase beads was washed thrice in PBS (pH 7.0) and incubated at room temperature for $30 \mathrm{~min}$ with the neoglycoprotein and $1 \mathrm{mCi}$ of $\mathrm{Na}^{125} \mathrm{I}$ (ICN, Plainview, NY). The beads were then centrifuged at $1,000 \mathrm{~g}$ for $5 \mathrm{~min}$ and the solution containing labeled neoglycoprotein was dialyzed against D-PBS for 48 h. Neoglycoprotein concentration was then adjusted to $2.7 \mathrm{mg} / \mathrm{ml}$. Final specific activity of all neoglycoproteins was about $0.6 \mu \mathrm{Ci} / \mathrm{nmol}$.

In addition to synthetic neoglycoproteins, asialofetuin (ASF; Sigma Chemical Co., St. Louis, MO) was similarly labeled and used. In this highly glycosylated glycoprotein, terminal sialyl residues are enzymatically removed to expose penultimate galactosyl residues. ASF, therefore, serves as a natural counterpart of galactosyl-BSA.

Binding assay. Cells were washed thrice in PBS (pH 7.4) and resuspended in D-PBS containing $1 \%$ BSA in the desired concentration $\left(10^{7}\right.$ cells $/ \mathrm{ml}$ in the standard assay). To $0.1 \mathrm{ml}$ of this cell suspension (containing $10^{6}$ cells) was added $0.1 \mathrm{ml}$ of radiolabeled neoglycoprotein in increasing concentrations. The total volume of incubate was adjusted to $0.3 \mathrm{ml}$ by addition of $0.1 \mathrm{ml}$ D-PBS. Incubation was done in microcentrifuge tubes at $4^{\circ} \mathrm{C}$ for $30 \mathrm{~min}$. Inhibition control was done in the presence of 40-fold cold neoglycoprotein. All incubations were done in triplicate and, in addition, all experiments were repeated at least five times to ensure reproducibility. The cells were then washed in D-PBS in a microcentrifuge, and the bound radioactivity was counted in a gamma counter. For time course studies the saturating concentrations of neoglycoproteins were similarly incubated with the cells for various time periods. Specific binding data were analyzed according to the method of Scatchard (25) to obtain the dissociation constant $\left(K_{d}\right)$, maximum binding $\left(B_{\max }\right)$, and the number of receptors per cell. The data were further analyzed according to the method of Barcroft and Hill (26) and Hill (27) to obtain the Hill coefficient and to determine the components of the binding.

To displace the bound radioactive ligand by cold soluble ligand, $10^{6}$ cells suspended in D-PBS containing $1 \%$ BSA were incubated with saturating concentration of radiolabeled neoglycoprotein at $4^{\circ} \mathrm{C}$ for 30 min. The bound radioactivity was then displaced by the addition of increasing concentrations of cold ligand. The cells were washed in D-PBS by centrifugation in a microcentrifuge and the radioactivity was counted in a gamma counter.

Fractionation of surface-bound and internalized ligand. After standard binding assay for $30 \mathrm{~min}$ at $4^{\circ} \mathrm{C}$ cells were washed in D-PBS to remove the excess unbound radioactivity. Cells were then resuspended in $0.3 \mathrm{ml}$ of D-PBS containing $1 \%$ BSA and were incubated for variable periods of time at $37^{\circ} \mathrm{C}$. At the end of each period, cells were transferred back to $4^{\circ} \mathrm{C}$ and surface-bound ligand was fractionated by adding $0.3 \mathrm{ml}$ of $0.5 \%$ pronase (28). Cells were then washed twice with D-PBS in a microcentrifuge and the radioactivities of the supernate and the cell pellet were counted separately as surface bound and internalized, respectively.

Cell labeling and enzymatic treatment. Progenitor cells were labeled by ${ }^{51} \mathrm{Cr}$ using standard methods (29). Briefly, $1 \mu \mathrm{Ci}$ of ${ }^{51} \mathrm{Cr}$, in the form of sodium chromate, specific activity $567 \mathrm{mCi} / \mathrm{mg}$ (ICN) was reacted with $1 \mathrm{ml}$ of cells $\left(3 \times 10^{7} /\right.$ cells $)$ for $1 \mathrm{~h}$ at room temperature in a conical centrifuge tube with agitation every $10 \mathrm{~min}$. Unbound radioactivity was removed from the mixture by centrifugation in D-PBS five times. The final level of radioactivity achieved was $30,000 \mathrm{cpm} / 10^{5}$ cells.

D2X cells were grown in 24-well plates (Linbro, Flow Labs, McLean, VA) to confluence. After reaching confluence the serumcontaining medium was replaced by $1 \mathrm{ml}$ of serum-free medium containing the desired enzymes. Enzymes were prepared in $0.1 \mathrm{ml}$ solutions in D-PBS and were added to the wells to achieve the desired final concentrations. The following enzymes (all from Sigma Chemical Co.) were used in the following final concentrations: neuraminidase, (Clostridium perfringens, $0.38 \mathrm{U} / \mathrm{ml}), \beta$-galactosidase $(E$. coli, $45 \mathrm{U} / \mathrm{ml})$, $\alpha$-mannosidase (almonds, $0.37 \mathrm{U} / \mathrm{ml}$ ), $\alpha$-L-fucosidase (bovine kidney, $0.13 \mathrm{U} / \mathrm{ml}$ ). Incubations were carried out sequentially in which one enzyme treatment was followed by others, as desired. Each treatment was done for $12 \mathrm{~h}$ at $37^{\circ} \mathrm{C}$, and subsequently the cells were washed twice with the medium. For control, serum-free medium without enzymes was used. 
After the completion of enzymatic treatment, D2X cells were overlayed with ${ }^{51} \mathrm{Cr}$-labeled $10^{6}$ B6SUT cells or $5 \times 10^{5} \mathrm{FDCP}-1$ cells. The appropriate number of progenitor cells were determined in preliminary experiments. Incubation was done in serum-free medium for $24 \mathrm{~h}$. Unbound cells were then removed and wells were thoroughly washed twice with the culture medium. The radioactivity unbound to D2X in all washes were determined. Bound cells were then removed by trypsinizing the wells for $10 \mathrm{~min}$ at $37^{\circ} \mathrm{C}$, and the radioactivity associated with bound cells was also counted. The ratio of bound radioactivity to total radioactivity was expressed as percentage of binding. Cell viability after enzyme treatments as determined by trypan blue exclusion test was always in excess of $99 \%$. All experiments were done in quadruplicate. The means and standard deviations were calculated and subjected to Student's $t$ test.

\section{Results}

Binding of neoglycoproteins: Fig. $1 \mathrm{~A}$ shows the results of binding of Gal-BSA to B6SUT cells as a function of ligand concentration. Nonspecific binding (binding in the presence of excess cold ligand) was linear and when this was subtracted from total binding, specific binding was obtained which was saturable at the ligand concentration of about $0.4 \times 10^{-6} \mathrm{M}$. The Scatchard analysis of the specific binding data is shown in Fig. 1 (inset), demonstrating a single population of receptors with $K_{d}$ of 2.25 $\times 10^{-7} \mathrm{M}$ with estimated number of receptors being $1 \times 10^{6} /$ cell. The data for Gal-BSA binding to FDCP-1 were similar with approximately similar affinity and receptor number (Fig. $2 A$ ). Similar data were obtained with both cell lines when radiolabeled asialofetuin was used as the ligand (data not shown). Fig. $1 A$ also shows that no specific binding occurred when Fuc-BSA was used, indicating the absence of specific receptor for this monosaccharide. The data for specific binding of Gal-BSA to murine mature neutrophils and red blood cells are also shown in Fig. $1 \mathrm{~A}$. No specific binding was detected, nor was any binding observed in human mature blood neutrophils, monocytes and red cells (data not shown).

Fig. $1 B$ shows the results of binding of Man-BSA to B6SUT as a function of ligand concentration. Again nonspecific binding was linear and specific binding was saturable. However, Scatchard analysis (inset) showed two components with low and high affinities. $K_{\mathrm{d}}, B_{\max }$, and receptor numbers per cell for both components are given in the figure. Binding data for FDCP-1 were similar, having two components with similar affinities and receptor numbers (Fig. $2 \mathrm{~B}$ ).

Since the affinities for the two components were close, the difference being slightly more than one order of magnitude, the data were subjected to Hill analysis. When all data were plotted together (Fig. 3), Hill coefficient was calculated to be 1.72 which, being more than 1 and close to 2 , confirms the presence of two distinct binding components. When each component was separately plotted, the Hill coefficients were 1.03 and 0.96 , respectively, for high- and low-affinity compo-
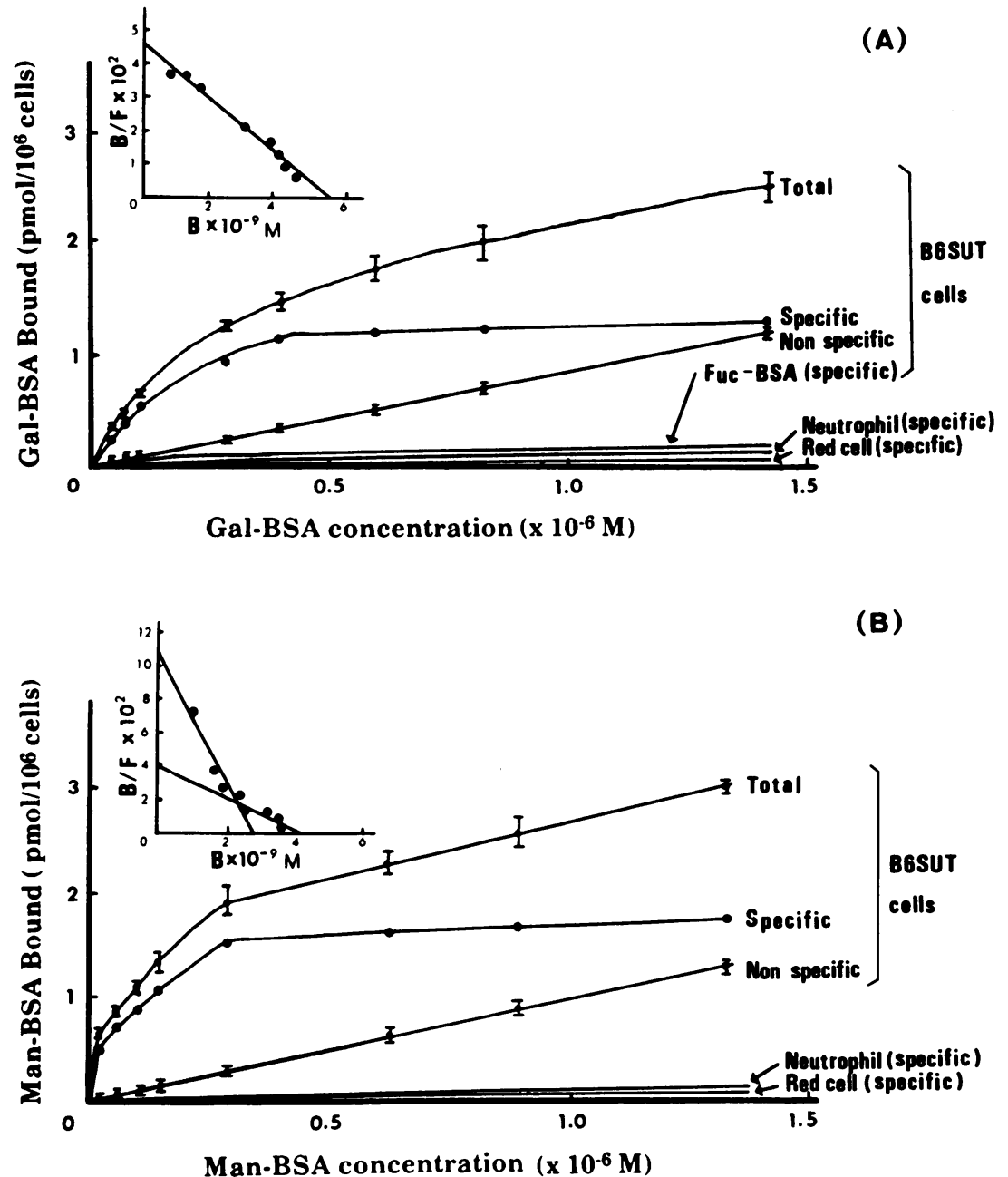

Figure 1. (A) Binding of ${ }^{125} \mathrm{I}-\mathrm{Gal}-\mathrm{BSA}$ to B6SUT as a function of ligand concentration. Various concentrations of ${ }^{125} \mathrm{I}$-Gal-BSA were incubated with $10^{6}$ cells at $4^{\circ} \mathrm{C}$ for $30 \mathrm{~min}$. in a total volume of $0.3 \mathrm{ml}$. The cells were then washed and cell-associated radioactivity was counted. This is shown as total binding. Parallel experiments were done in the presence of 40 -fold cold ligand. Cell-associated radioactivity is shown as nonspecific binding which is linear. The latter was subtracted from total binding to obtain specific binding which is saturable at the ligand concentration of about $0.4 \times 10^{-6} \mathrm{M}$. (Inset) Scatchard plotting of specific binding data, showing a single receptor population. $K_{\mathrm{d}}, 2.25$ $\times 10^{-7} \mathrm{M} ; B_{\max }, 1.66 \mathrm{pmol} / 10^{6}$ cells; and receptor number, $1.00 \times 10^{6} /$ cell. This figure also shows the absence of specific binding for B6SUT cells with Fuc-BSA as ligand, and for mature murine neutrophils and red cells with Gal-BSA as ligand. $(B)$ Binding of ${ }^{125} \mathrm{I}-\mathrm{Man}-\mathrm{BSA}$ to B6SUT as a function of ligand concentration. The experimental conditions were as in $A$. (Inset) Scatchard plotting of specific binding data. The binding appears to have two components with high and low affinities. High: $K_{\mathrm{d}}$, $2.51 \times 10^{-8} \mathrm{M} ; B_{\max }, 1.23 \mathrm{pmol} / 10^{6}$ cells; receptor number, $7.43 \times 10^{5} /$ cell. Low: $K_{\mathrm{d}}, 1.02$ $\times 10^{-7} \mathrm{M} ; B_{\max }, 0.61 \mathrm{pmol} / 10^{6}$ cells; receptor number, $3.67 \times 10^{5} /$ cell. This figure also shows the absence of specific binding of ${ }^{125}$ I-Man-BSA by murine mature neutrophils and red cells. 

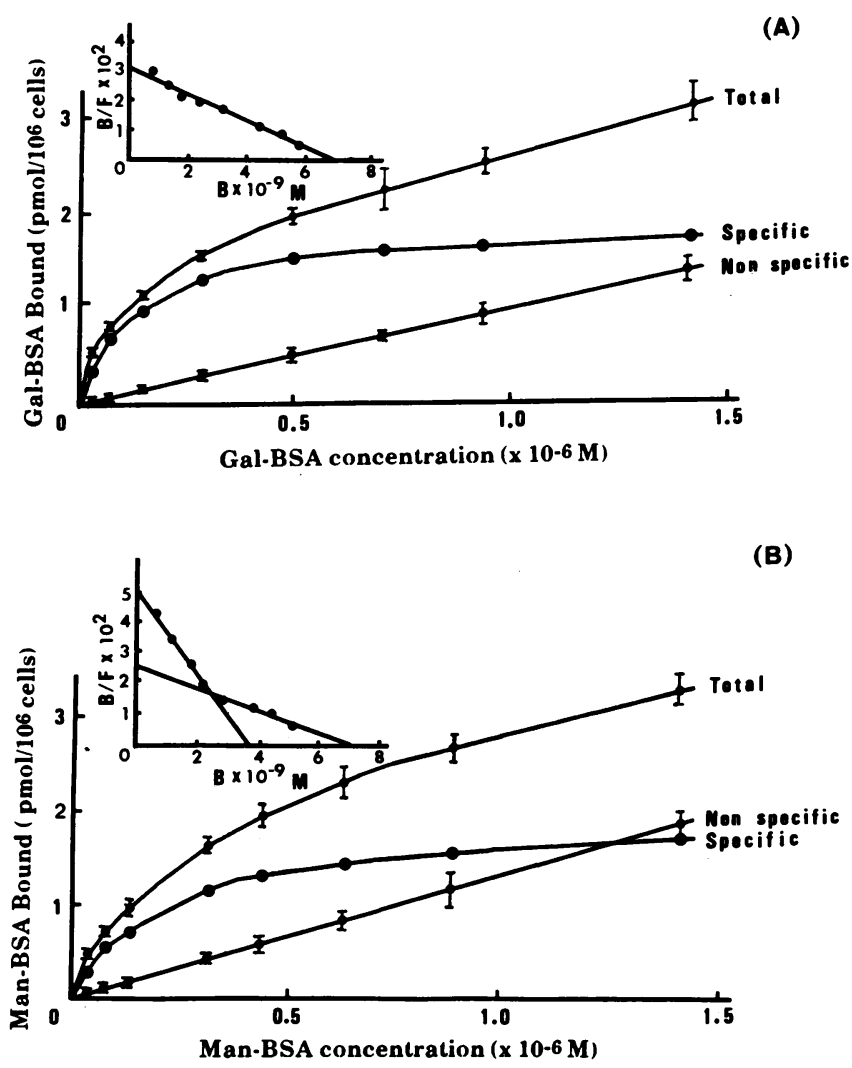

Figure 2. Binding of ${ }^{125} \mathrm{I}$-labeled Gal-BSA $(A)$ and Man-BSA $(B)$ to FDCP-1 cells. Experimental conditions are as in Fig. 1. Scatchard plots of specific binding data are shown in the insets with appropriate parameters given: $(A) K_{\mathrm{d}}, 2.30 \times 10^{-7} \mathrm{M} ; B_{\max }, 2.01 \mathrm{pmol} / 10^{6}$ cells; receptor number, $1.21 \times 10^{6} /$ cell. $(B)$ High: $K_{d}, 6.94 \times 10^{-8} \mathrm{M}$; $B_{\max }, 1.14 \mathrm{pmol} / 10^{6}$ cells; receptor number, $6.84 \times 10^{5} /$ cell. Low: $K_{\mathrm{d}}, 3.02 \times 10^{-7} \mathrm{M} ; B_{\max }, 1.13 \mathrm{pmol} / 10^{6}$ cells; receptor number, 6.86 $\times 10^{5} /$ cell. Again Gal-BSA appears to have a single receptor population with binding parameters comparable to those of B6SUT receptors. Similarly, Man-BSA appears to have two receptor populations with parameters having the same order of magnitude as those of B6SUT receptors.

nents for B6SUT cells (Fig. $4 A$ ) and 0.99 and 0.91 for FDCP-1 cells (Fig. $4 \mathrm{~B}$ ). These coefficients, being close to unit, further confirmed that the two components were indeed separate, indicating that mannosyl receptors have two distinct components with different affinities. Specific binding of Man-BSA for mature murine neutrophils and red blood cells is also shown in Fig. $1 B$. No binding was detected, nor was any binding detected for human blood neutrophils, monocytes, and red cells (data not shown).

Fig. 5 demonstrates that the magnitude of binding of Man-BSA for B6SUT cells was a linear function of cell number. Similar results were obtained for Gal-BSA as well as both neoglycoproteins with FDCP-1 cells.

Fig. 6 shows the binding of Man-BSA at a saturable concentration as a function of time for B6SUT cells. Binding reached a plateau within minutes and remained so for the period of study. Similar findings were observed for Gal-BSA and for both neoglycoproteins with FDCP-1 cells.

Fractionation of surface-bound and internalized ligands. To find out if the ligands were internalized at $37^{\circ} \mathrm{C}$, incubation was done at this temperature with saturable concentration of

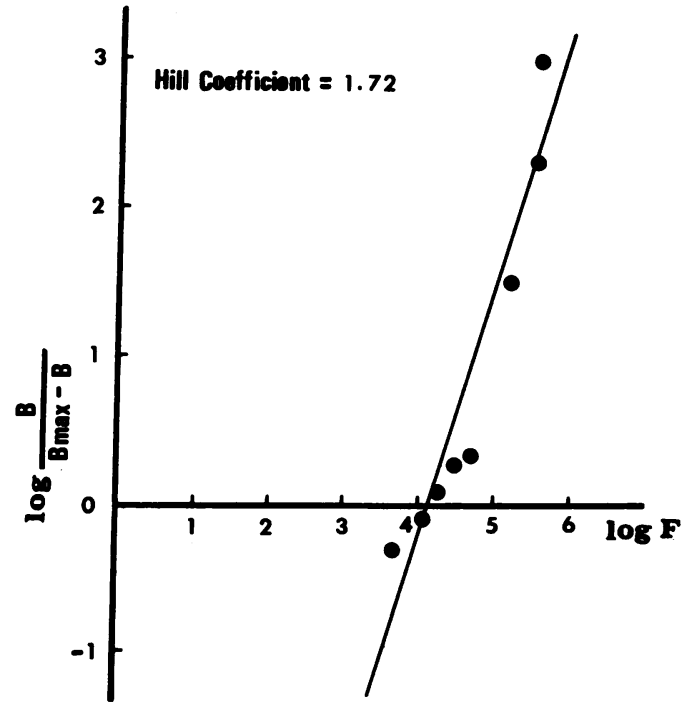

Figure 3. Hill plot of specific binding data for Man-BSA bound to B6SUT. Hill coefficient of 1.72 suggests two receptor populations. Similar coefficient was obtained for Man-BSA bound to FDCP-1.
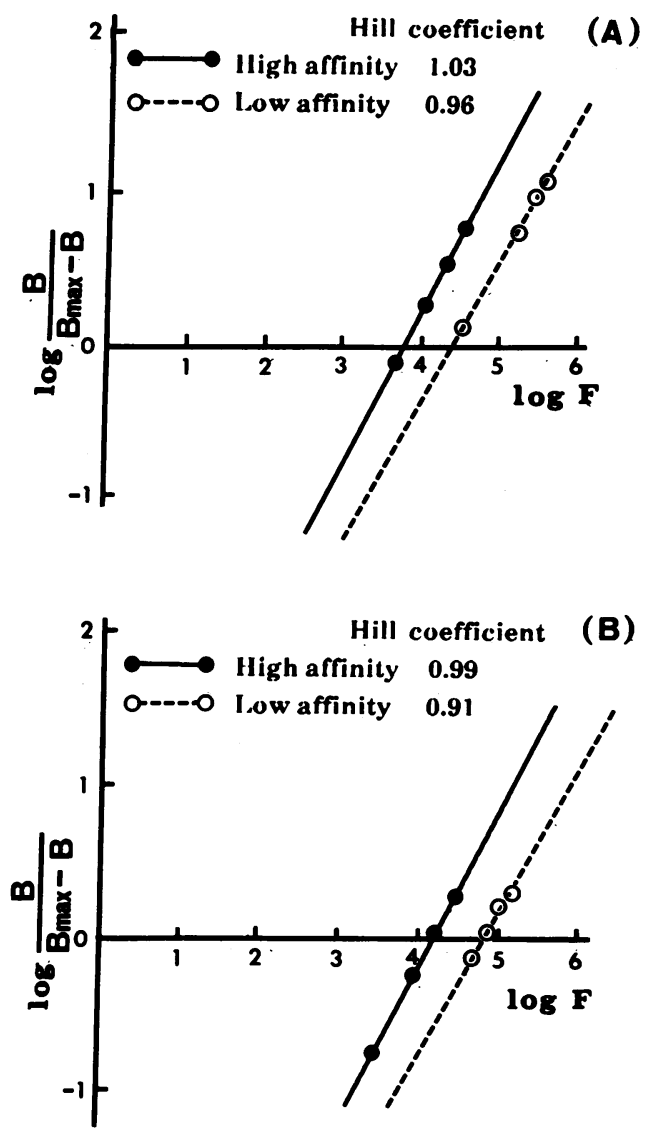

Figure 4. (A) Hill analysis of specific binding data for Man-BSA bound to B6SUT, plotted separately for high and low affinity components. The coefficient calculated for both components is close to unit, suggesting that the two components are indeed real and not merely apparent. $(B)$ Similar plotting for Man-BSA binding to FDCP-1. 


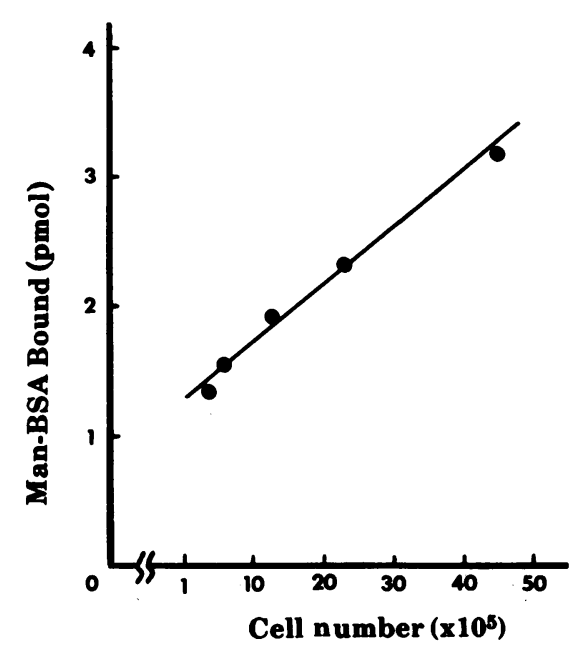

Figure 5. Man-BSA binding to B6SUT as a function of cell number. Saturating concentration $\left(1 \times 10^{-6} \mathrm{M}\right)$ of radiolabeled ligand was incubated with different cell number at $4^{\circ} \mathrm{C}$ for $30 \mathrm{~min}$. The cell-associated radioactivity was then counted and specific binding was calculated as in Fig. 1. The binding is a linear function of cell number. Similar data were obtained for Gal-BSA.

radiolabeled ligands. At different time points after the initiation of the incubation, samples were removed and surfacebound and internalized ligands were fractionated, using pronase treatment. The data for Man-BSA with B6SUT as target cells are shown in Fig. 7, indicating that no internalization occurred. Similar data were obtained with Gal-BSA and B6SUT cells as well as with both neoglycoproteins and FDCP-1 as target cells.

Displacement experiments. To determine if the bound radiolabeled ligands could be displaced by excess cold ligand, ${ }^{125}$ I-labeled ligands at a saturable concentration were bound at $4^{\circ} \mathrm{C}$ to the cells which were washed to remove excess unbound radiolabeled ligands. The cells, now saturated at the surface with ${ }^{125}$ I-labeled ligands, were transferred to the buffer containing variable concentrations of cold ligands at $4^{\circ} \mathrm{C}$. The percentage of displaced radiolabeled ligands was then calculated. The results for B6SUT cells are shown in Fig. $8 \mathrm{~A}$. Both Man-BSA and Gal-BSA were displaced completely as the concentration of cold ligand increased. Displacement gave a sig-

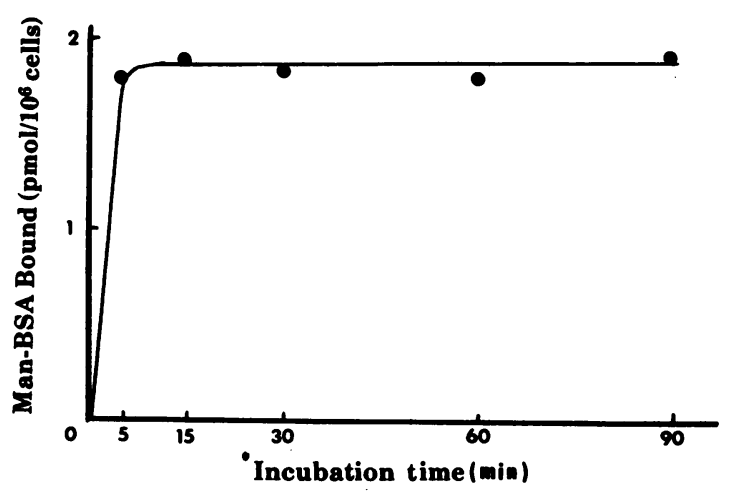

Figure 6. Time course for specific binding of Man-BSA to B6SUT cells. Saturating concentration $\left(1 \times 10^{-6} \mathrm{M}\right)$ of radioactive ligand was incubated with $10^{6}$ cells at $4^{\circ} \mathrm{C}$. Saturation plateau is reached within $5 \mathrm{~min}$ and maintained thereafter. Similar data were obtained for Gal-BSA.

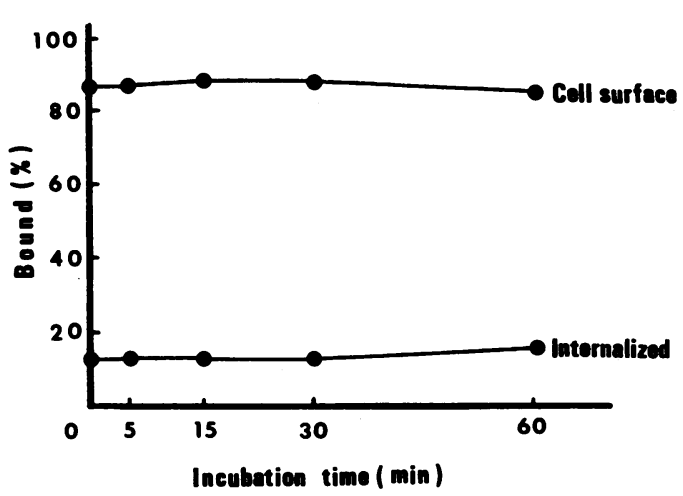

Figure 7. Fractionation of surface-bound and internalized ligand for Man-BSA incubated with B6SUT cells. Methodology is given in the text. No internalization occurred during the period of observation. Similar data were obtained for Gal-BSA.

moid-shaped curve, typical of ligand displacement from receptors $(30,31)$. Similar data were observed when FDCP-1 cells were used as target cells.

To explore the relationship between receptors for the two ligands, we attempted to displace, in a similar manner, bound radiolabeled Gal-BSA in the presence of different concentrations of cold Man-BSA. The results, shown in Fig. 8 B, again demonstrate a sigmoid-shaped curve of displacement. However, when radiolabeled Man-BSA was bound to the cells, and its displacement was attempted with different concentrations of cold Gal-BSA, a biphasic displacement curve was obtained (Fig. $8 \mathrm{~B}$ ). In the first phase, displacement began at the concentration of $1.6 \times 10^{-10} \mathrm{M}$ and then reached a plateau. A second phase of displacement began at a relatively high concentration between $10^{-6}$ and $10^{-5} \mathrm{M}$ and this continued until completion.
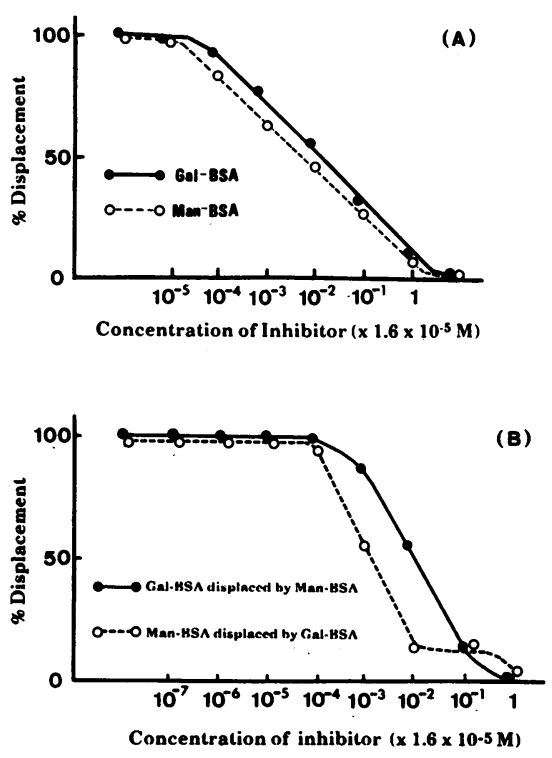

Figure 8. (A) Displacement of radioactive ligands by homologous cold ligands. Conditions of experiments are described in the text. Both ligands gave typical sigmoid-shaped curves of displacement. $(B)$ Displacement of radioactive ligands by heterologous cold ligands. Man-BSA displaced Gal-BSA with a typical sigmoid-shaped curve. However, Gal-BSA displaced Man-BSA in a biphasic manner, consistent with the two affinity components of Man-BSA binding. 
Binding to stromal cells. The results are shown in Table I. Binding of FDCP-1 cells to D2X was significantly $(P<0.01)$ enhanced by treatment of stromal cells with neuraminidase which removes terminal sialyl residues and exposes more galactosyl residues that are in penultimate position. A similar trend in binding of B6SUT cells was also observed by neuraminidase treatment, but the difference was not statistically significant. In both cell lines, sequential treatment with neuraminidase and $\beta$-galactosidase (that remove both sialyl and galactosyl residues) almost totally abolished the binding, indicating the involvement of exposed galactosyl residues in the binding. Similar abolishment of the binding was observed after sequential treatment with neuraminidase, $\beta$-galactosidase, and $\alpha$-mannosidase. The differences in the binding compared to control (no treatment) were highly significant $(P<0.001)$. By contrast, when the sequence of enzymatic treatment was reversed, so that neuraminidase treatment was used last, and consequently galactosyl and mannosyl residues of membrane glycoconjugates would still be covered by sialyl residues and would not be available to the enzymatic cleavage, no inhibition of binding was noted. Slight enhancement of binding that was seen could be attributed to the removal of sialyl residues, during the last part of the sequence, leading to the exposure of more penultimate galactosyl residues. Treatment with $\alpha$-fucosidase had no effect on the binding.

\section{Discussion}

Our previous studies have indicated that hemopoietic progenitor cells possess membrane lectins with specificities for galactosyl and mannosyl residues of glycoconjugates on stromal cell membrane. Molecular interactions of the lectins with specific configuration of the carbohydrate residues appear to lead to the binding (homing) of progenitor cells to stromal cells. Thus, synthetic neoglycoproteins, containing these carbohydrate residues, can inhibit reconstitution of hemopoiesis both in vivo (12) and in vitro $(10,11)$.

Table I. Quantitative Binding of ${ }^{51}$ Cr-labeled FDCP-1 and B6SUT to Stromal Cells with and without Enzymatic Treatment of Stromal Cell Membrane Glycoconjugates

\begin{tabular}{lcc}
\hline Enzymatic treatment & FDCP-1 binding & B6SUT binding \\
\hline & $\%$ & $\%$ \\
No treatment & $37.9 \pm 5.1$ & $20.8 \pm 2.0$ \\
$\mathrm{~N}$ & $48.6 \pm 1.7^{\S}$ & $22.8 \pm 1.3$ \\
$\mathrm{~N} \rightarrow \mathrm{G}$ & $3.9 \pm 0.8^{\| 1}$ & $6.7 \pm 1.7^{\| 1}$ \\
$\mathrm{~N} \rightarrow \mathrm{G} \rightarrow \mathrm{M}$ & $2.2 \pm 0.2^{\| 1}$ & $3.9 \pm 0.5^{\mid 1}$ \\
$\mathrm{G} \rightarrow \mathrm{M} \rightarrow \mathrm{N}$ & $42.0 \pm 1.0$ & $22.2 \pm 2.3$ \\
$\mathrm{M} \rightarrow \mathrm{G} \rightarrow \mathrm{N}$ & $43.1 \pm 1.9$ & $20.6 \pm 0.6$ \\
$\mathrm{~F}$ & $36.0 \pm 2.4$ & $19.8 \pm 2.0$
\end{tabular}

\footnotetext{
* Abbreviations: N, neuraminidase; G, $\beta$-galactosidase; $M, \alpha$-mannosidase; F, $\alpha$-fucosidase. The arrows indicate the sequential order of enzymatic treatment.

₹ Percentage of binding was calculated as described in the text.

${ }^{8} P<0.01$ when compared to no treatment.

" $P<0.001$ when compared to no treatment.

' $\mathrm{P}<0.05$ when compared to $\mathrm{N} \rightarrow \mathrm{G}$.

Data represent mean \pm SD of quadruplicate experiments.
}

Because the marrow cell population is heterogeneous, with progenitor cells occurring at low frequencies, and because no methods are available to obtain purified preparations of marrow progenitor cells for receptor studies, in the present work we used two cloned hemopoietic progenitor cells and radiolabeled synthetic neoglycoproteins to characterize these membrane lectins. Both B6SUT (pluripotent) and FDCP-1 (bipotent) cells possess membrane lectins with galactosyl and mannosyl but not fucosyl specificities. The number of these receptors is a function of the number of cells used in the binding assays.

That these receptors are indeed involved in the binding (homing) of progenitor cells to stromal cells is evident by the binding assay in which radiolabeled FDCP-1 and B6SUT cells are bound to the cloned stromal cell line D2X. Normally about a third of progenitor cells bind to $\mathrm{D} 2 \mathrm{X}$. This proportion increases when D2X membrane is treated with neuraminidase which removes sialyl residues of membrane glycoconjugates to expose penultimate galactosyl residues. On the other hand, when galactosyl and mannosyl residues are also removed enzymatically, virtually no binding is observed. Binding is not similarly affected after treatment with fucosidase. Nor is it affected when galactosidase and mannosidase are used before neuraminidase, when galactosyl and mannosyl residues are still covered by sialyl residues and are not available to enzymatic cleavage. These results indicate that galactosyl and mannosyl receptors of progenitor cells are indeed involved in the binding of these cells to the stroma. Stromal cell carbohydrate residues in these experiments serve as membrane-bound ligands, similar to soluble neoglycoproteins. To further confirm the involvement of stromal membrane glycoconjugates in binding of progenitor cells, we attempted to inhibit glycosylation in D2X by tunicamycin. However, this treatment led to reduced plating efficiency and abrogation of adherence capacity and failed to yield conclusive results.

The presence of membrane receptors on progenitor cells with defined specificities confirms our previous observation using the agglutination technique which demonstrates that both Gal-BSA and Man-BSA, but not Fuc-BSA, can selectively agglutinate CFU-S and CFU-GM from whole marrow cell populations (13). These studies, therefore, indicate that the receptors detected in these cloned cell lines do, indeed, represent those present in hemopoietic progenitors in whole marrow cell suspensions. From a clinical point of view, these ligands may have potential that could be exploited to enrich progenitor cells from marrow cell suspensions for bone marrow transplantation. This area deserves further exploration. That these receptors selectively interact with Gal-BSA (or ASF) and Man-BSA, but not Fuc-BSA, is also consistent with our previously reported inhibition studies which indicate that fucosyl-containing neoglycoprotein does not inhibit reconstitution of hemopoiesis (10-12).

The observation that mature circulating blood cells (murine neutrophils and red cells as well as human blood neutrophils, monocytes, and red cells) lack these binding specificities indicates that the synthesis of these homing receptors is developmentally regulated. They are present in early stages of development. With maturation, cells may then lose these receptors allowing them to be released into the circulation. Thus, mature circulating cells do not possess receptors. The absence of mannosyl receptors on mature human monocytes has been previously reported $(32,33)$. 
While galactosyl receptors appear to be a single population as indicated by Scatchard analysis, mannosyl receptors appear to be two populations with different affinities and different receptor numbers. The low-affinity mannosyl receptors have a $K_{\mathrm{d}}$ in the range of that for galactosyl receptors $\left(1.02 \times 10^{-7} \mathrm{M}\right.$ vs. $\left.2.25 \times 10^{-7} \mathrm{M}\right)$. Because the two affinities for mannosyl receptors are very close, differing only by one order of magnitude, the question is raised if indeed mannosyl receptors have two components, or alternatively, this difference may be more apparent than real, i.e., only one component may be involved. To clarify this point, we subjected the data to Hill analysis. In this type of analysis, when only one receptor component is involved, the calculated Hill coefficient is around $1.0(26,27)$. In the case of mannosyl receptors, the Hill coefficient of 1.72 suggests more than one and probably two receptor components. This is further confirmed when the two components are separately subjected to Hill analysis. The Hill coefficient for both components is then calculated to be around 1.0, suggesting that indeed two different components are involved in both cell lines.

In line with this interpretation are the displacement experiments, which indicate that each ligand in nonradiolabeled form can displace bound homologous radiolabeled ligand. The displacement curve gives a typical sigmoid-shaped curve as a function of the concentration of cold ligand $(30,31)$. Similarly, cold Man-BSA, which has two binding components, one coinciding in affinity with that of Gal-BSA, can displace radiolabeled Gal-BSA with a similar sigmoid-shaped curve. But the cold Gal-BSA, with its single affinity component, can displace radiolabeled Man-BSA in two phases. Most of the bound Man-BSA can be displaced with a concentration of $10^{-7}$ to $10^{-8} \mathrm{M}$ cold Gal-BSA, but much higher concentrations of cold Gal-BSA is needed to displace it completely. This doublephase displacement curve suggests that galactosyl and mannosyl receptors may be in some way interacting and possibly forming different parts of a single molecular complex. It is to be noted that, in both FDCP-1 and B6SUT cells, the total number of mannosyl receptors (both high- and low-affinity components) is almost equal to the number of galactosyl receptors. This again suggests the presence of a single molecular species of receptors, interacting similarly with all galactosyl ligands, but in two different ways with mannosyl ligands. More recent evidence from our laboratory by purification of these receptors, using affinity column chromatography (to be published later), indicates that the receptor for both galactosyl and mannosyl residues indeed consists of a single molecular species with an $M_{\mathrm{r}}$ of $110,000 \mathrm{kD}$.

It is also to be noted that the ligands used in these studies are synthetic neoglycoproteins which cannot be considered natural counterparts of membrane glycoconjugates. It is, therefore, possible that the binding characteristics of these neoglycoproteins are entirely different from those reactive glycoconjugates which may be present on hemopoietic stromal cells. The relatively low-affinity data, obtained in these studies, may also be explained on this basis. Nonetheless, the affinity for binding of progenitor cells to stromal cells is expected to be low, because the binding is transient and, upon maturation, cells must be released from stroma to enter the blood stream. In this context, high-affinity binding can potentially prevent the release of mature cells, leading to ineffective hemopoiesis. In fact, tight binding of hemopoietic cells to marrow stroma has been shown to cause ineffective hemopoiesis (34-37).
The absence of internalization of the ligands, documented in these studies, is only expected. Soluble ligands in this work represent stromal cells, and it is not expected that the binding of progenitor cells to stromal cells leads to internalization of the latter cells. It is possible that the binding may activate a second messenger system intracellularly and this can ultimately regulate proliferation and differentiation of progenitor cells.

It should also be noted that a similar membrane lectin, with somewhat different specificity has been described in lymphocytes and it has been demonstrated that this lectin mediates lymphocyte homing to the high endothelium of postcapillary venules (38-41). Interaction between carbohydrates and proteins, therefore, may be a more general phenomena than heretofore recognized in determining the pattern of cellular traffic in the organisms.

\section{Acknowledgments}

The authors thank Ms. Jackie Jordan for secretarial assistance.

This work was supported by National Institutes of Health grant DK-30142 and a Veterans Administration Merit Review grant.

\section{References}

1. Tavassoli, M. 1975. Studies on hemopoietic microenvironments. Exp. Hematol. 3:213-216.

2. Tavassoli, M., and W. H. Crosby. 1968. Transplantation of marrow to extramedullary sites. Science (Wash. DC). 161:54-56.

3. Wolf, N. S., and J. J. Trentin. 1968. Hemopoietic colony studies. $\mathrm{V}$. Effect of hemopoietic organ stroma on differentiation of pluripotent stem cells. J. Exp. Med. 127:205-214.

4. Thomas, E. D. 1976. Progress in marrow transplantation. JAMA (J. Am. Med. Assoc.) 235:611-612.

5. Robertson, M. 1979. Bone-marrow transplantation: man and mouse. Nature (Lond.). 280:720-721.

6. Greig, R. G., and M. N. Jones. 1977. Mechanisms of intercellular adhesion. Biosystems. 9:43-55.

7. Sharon, N., and H. Lis. 1987. A century of lectin research. Trends Biochem. Sci. 12:488-491.

8. Samlowski, W. E., and R. A. Daynes. 1985. Bone marrow engraftment efficiency is enhanced by competitive inhibition of the hepatic asialoglycoprotein receptor. Proc. Natl. Acad. Sci. USA. 82:2508-2512.

9. Kataoka, M., and M. Tavassoli. 1984. Synthetic neoglycoproteins: a class of reagents for detection of sugar-recognizing substances. J. Histochem Cytochem. 32:1091-1098.

10. Aizawa, S., and M. Tavassoli. 1987. In vitro homing of hemopoietic stem cell is mediated by a recognition mechanism with galactosyl and mannosyl specificity. Proc. Natl. Acad. Sci. USA. 84:44854489.

11. Aizawa, S., and M. Tavassoli. 1987. Interaction of murine granulocyte-macrophage progenitors and supporting stroma involves a recognition mechanism with galactosyl and mannosyl specificities. $J$. Clin. Invest. 80:1698-1705.

12. Aizawa, S., and M. Tavassoli. 1988. Molecular basis of the recognition of intravenously transplanted hemopoietic cells by bone marrow. Proc. Natl. Acad. Sci. USA. 85:3180-3183.

13. Aizawa, S., and M. Tavassoli. 1988. Detection of membrane lectins on the surface of hemopoietic progenitor cells and their changing pattern during differentiation. Exp. Hematol. 16:325-329.

14. Ihle, J. N., J. Keller, J. S. Greenberger, L. Henderson, R. A. Yetter, and H. C. Morse III. 1982. Phenotypic characteristics of cell lines requiring interleukin 3 for growth. J. Immunol. 129:1377-1383. 
15. Greenberger, J. S., M. A. Sakakeeny, R. K. Humphries, C. J. Eaves, and R. J. Eckner. 1983. Demonstration of permanent factordependent multipotential (erythroid/neutrophil/basophil) hematopoietic progenitor cell lines. Proc. Natl. Acad. Sci. USA. 80:2931-2935.

16. Greenberger, J. S., M. A. Sakakeeny, L. M. Davis, W. C. Maloney, and D. Reid. 1984. Biologic properties of factor-independent nonadherent hematopoietic and adherent preadipocyte cell lines derived from continuous bone marrow culture. Leuk. Res. 8:363-375.

17. Hardy, C. L., T. Kishimoto, K. Harjes, M. Tavassoli, and J. S. Greenberger. 1986. Homing of a cloned multipotential stem cell line in spleen and intraperitoneal membrane. Exp. Hematol. 14:636-642.

18. Dexter, T. M., J. Garland, D. Scott, E. Scolnick, and D. Metcalf. 1980. Growth of factor-dependent hemopoietic precursor cell lines. J. Exp. Med. 152:1036-1047.

19. Hapel, A. J., H. S. Warren, and D. A. Hume. 1984. Different colony-stimulating factors are detected by the interleukin-3-dependent cell lines FDCP-1 and 32D cl-23. Blood. 64:786-790.

20. Packard, B. S., M. Tavassoli, G. L. Dale, and E. Beutler. 1982. A method for the establishment and long-term maintenance of in vitro monocytic cultures with functional and morphological homogeneity. Blood. 60:623-626.

21. Kataoka, M., S. W. Chapman, and M. Tavassoli. 1984. Characterization of human monocytes maintained in long-term culture with functional and morphological homogeneity. Exp. Hematol. 12:183190.

22. Lowry, O. H., N. J. Rosebrough, A. L. Farr, and R. J. Randall. 1951. Protein measurement with the Folin-phenol reagent. J. Biol. Chem. 193:265-275.

23. Francois, C., R. D. Marshall, and A. Neuberger. 1962. Carbohydrates in protein. 4 . The determination of mannose in hen's-egg albumin by radioisotope dilution. Biochem. J. 83:335-341.

24. David, G. S. 1972. Solid state lactoperoxidase: a highly stable enzyme for simple gentle iodination of proteins. Biochem. Biophys. Res. Commun. 48:464-471.

25. Scatchard, G. 1949. The attractions of proteins for small molecules and ions. Ann. NY Acad. Sci. 51:660-672.

26. Barcroft, J., and A. V. Hill. 1910. The nature of oxyhaemoglobin, with a note on its molecular weight. J. Physiol. (Lond.). 39:411428.

27. Hill, A. V. 1910. A new mathematical treatment of changes of ionic concentration in muscle and nerve under the action of electric currents, with a theory as to their mode of excitation. J. Physiol. (Lond.). 11:190-324.

28. Karin, M., and B. Mintz. 1981. Receptor-mediated endocytosis of transferrin in developmentally totipotent mouse tetratocarcinoma stem cells. J. Biol. Chem. 256:3245-3252.

29. Hebbel, R. P., M. A. B. Boogaerts, J. W. Eaton, and M. H. Steinberg. 1980. Erythrocyte adherence to endothelium in sickle-cell anemia a possible determinant of disease severity. N. Engl. J. Med. 302:992-995.

30. Ariens, E. J., A. M. Simonis, and J. M. Van Rossum. 1964. Drug-receptor interaction: Interaction of one or more drugs with different receptor systems. In Molecular Pharmacology. Vol. 1. E. J. Ariens, editor. Academic Press, Inc., New York. 287-393.

31. Ariens, E. J., A. J. Beld, J. F. Rodrigues de Miranda, and A. M. Simonis. 1979. In The Receptors. Vol. 1. R. D. O'Brien, editor. Plenum Press, New York. 33-91.

32. Shepherd, V. L., E. J. Cambell, R. M. Senior, and P. D. Stahl. 1982. Characterization of the mannose/fucose receptor on human mononuclear phagocytes. J. Reticuloendothel. Soc. 32:423-431.

33. Kataoka, M., and M. Tavassoli. 1985. Development of specific surface receptors recognizing mannose-terminal glycoconjugates in cultured monocytes: a possible early marker for differentiation of monocyte into macrophage. Exp. Hematol. 13:44-50.

34. Breton-Gorius, J., G. Flandrin, M. T. Daniel, and J. C. Brouet. 1973. Septate-like junctions acquired by erythroblasts in a case of refractory anemia. Scand. J. Haematol. 10:219-224.

35. Frisch, B., S. M. Lewis, and M. Swan. 1976. Intercellular contacts between erythroid precursors in bone marrow in dyserythropoiesis. Br. J. Haematol. 33:469-475.

36. Frisch, B., and S. M. Lewis. 1978. Cell junctions in dyserythropoiesis. Virchows Archiv. B. 28:351-360.

37. Tavassoli, M., and M. Shaklai. 1979. Junctional structures in haemopoiesis: a study of bone marrow using freeze-fracture and lanthanum impregnation techniques. Br. J. Haematol. 43:235-241.

38. Butcher, E. C., R. G. Scollay, and I. L. Weissman. 1979. Lymphocyte adherence to high endothelial venules: characterization of a modified in vitro assay, and examination of the binding of syngeneic and allogeneic lymphocyte populations. J. Immunol. 123:1996-2003.

39. Gallatin, W. M., I. L. Weissman, and E. C. Butcher. 1983. A cell-surface molecule involved in organ-specific homing of lymphocytes. Nature (Lond.). 304:30-34.

40. Gallatin, M., T. P. St. John, M. Siegelman, R. Reichert, E. C. Butcher, and E. L. Weissman. 1986. Lymphocyte homing receptors. Cell. 44:673-680.

41. Stoolman, L. M., T. A. Yednock, and S. D. Rosen. 1987. Homing receptors on human and rodent lymphocytes-evidence for a conserved carbohydrate-binding specificity. Blood. 70:1842-1850. 